\section{Efficient Method to Generate Homologous Recombinant Baculovirus Genomes in E. coli}

BioTechniques 32:783-788 (April 2002)

\begin{abstract}
Here we describe a convenient method to generate homologous recombinant baculoviral genomes in $\mathrm{E}$. coli. The recombination takes place with the aid of recombination enzymes provided by the phage $\lambda$ Red system between a bacmid (a baculoviral genome that can replicate in bacteria) and a linear fragment. Proof of concept was provided when the cathepsin gene (v-cath) of the Helicoverpa armigera single nucleocapsid nucleopolyhedrovirus (HaSNPV) was replaced by the chloramphenicol resistance gene $\left(\mathrm{Cm}^{\mathrm{R}}\right)$. First, $\mathrm{Cm}^{\mathrm{R}}$ was inserted between the flanking sequences of the HaS$N P V$ v-cath. Each of the flanking regions was about $1 \mathrm{~kb}$. The fragment was linearized and electroporated into bacteria containing both the HaSNPV bacmid and the $\lambda$ Red system. Recombinant bacmids resistant to chloramphenicol were selected. In comparison to the standard co-transfection/plaque assays, this method significantly reduces the time required to construct baculovirus knockout mutants. It may also be useful in the manipulation of other large viral genomes.
\end{abstract}

\section{INTRODUCTION}

With the completion of many baculovirus genome sequences, numerous uncharacterized open reading frames (ORFs) were found within the genomes (5). One way to understand the functions of unknown ORFs is to generate deletion mutants. Traditionally, the baculoviral recombinants were generated by homologous recombination between a transfer vector and the viral DNA. The recombinant viruses are then screened and purified by standard plaque assays (11). One disadvantage of this method is that it takes 4-6 weeks to generate recombinants. In 1993, Luckow and coworkers (9) developed a method (Bac-
to-Bac) for generating site-specific recombinant baculoviral genome in $E$. coli. In this method, the mimiF replicon and a transposon target site were inserted into the baculoviral genome, generating a genome (bacmid) that could propagate in both $E$. coli and insect cells. With the help of a transpotase from a plasmid, a gene cloned between the right and left arms of $\mathrm{Tn} 7$ could be inserted into the transposon target site of the viral genome. As the transposon target site was introduced into a specific site (e.g., polyhedrin gene locus) of the bacmid DNA, the Bac-to-Bac system is only useful for generating recombinants with gene insertions into the particular site, but not for constructing homologous recombinants at other sites in the baculoviral genome.

In E. coli, many methods have been developed to disrupt the target gene (4,6,8,10,12-14). Recently, Datsenko and Wanner (4) have described a gene replacement method based on the phage $\lambda$ Red system. The phage $\lambda$ Red system is made of three gene products: Exo, Bet, and Gam (7), which can function in E. coli. The homologous recombination is initiated with the help of Exo and Bet. Exo degrades processively from the $5^{\prime}$ end of the linear fragment, and Bet binds to the remaining $3^{\prime}$ single-stranded tail, protecting and preparing the recessed DNA for homologous strand invasion. Gam appears to optimize the functions of Exo and Bet. By providing phage $\lambda$ Red recombinase, recombination between the linear fragment containing the flanking sequences of the target gene and the bacterial chromosome has been achieved in E. coli. This system has been successfully used to generate different deletions of chromosomal genes (4).

Helicoverpa armigera single nucleocapsid nucleopolyhedrovirus (HaSNPV) was first isolated from natural diseased $H$. armigera larvae (15) and has been successfully used to control cotton bollworm in China (16). As a prelude to understanding the detailed functions of HaSNPV and to enhance its insecticidal activity by genetic engineering, the genome has been entirely sequenced (3). In our laboratory, a bacmid DNA (HaBacHZ8) of HaSNPV was constructed recently $(H$. Wang et al., unpublished data). In this paper, the 
procedure of generating homologous recombinant HaSNPV in E. coli based on the phage $\lambda$ Red system is described. The locus of the viral cathepsin was used to prove the concept.

\section{MATERIALS AND METHODS}

\section{Bacterial Strains, Plasmids, and Bacmid DNA}

E. coli strain DH5 $\alpha$ was used for propagating plasmids. The E. coli strain BW25113 (pKD46) (kindly provided by Dr. Barry L Wanner) was used for gene replacement experiments. The genetic background of BW25113 is lacI $^{q} \quad \mathrm{rrnB}_{T 14} \quad \mathrm{LlacZ}_{w 116} \quad$ hsdR514 $\triangle a r a B A D_{A H 33} \triangle r h a B A D_{L D 78}$. The plasmid pKD46 contains the phage $\lambda$ Red system under the control of arabinose promoter (4). After the recombinant bacmids were generated, they were retained in E. coli strain DY380 (kindly provided by Dr. Donald L Court) (14). All E. coli strains were grown in LB medium with the appropriate antibiotic selection. The final concentrations of the antibiotics are $100 \mu \mathrm{g} / \mathrm{mL}$ for ampicillin, $50 \mu \mathrm{g} / \mathrm{mL}$ for kanamycin, and 25 $\mu \mathrm{g} / \mathrm{mL}$ for chloramphenicol.

The pKD3 donor plasmid containing chloramphenicol resistance gene $\left(C m^{R}\right)$ was kindly provided by Dr. Barry L. Wanner (4). pGEM ${ }^{\circledR}$-T Easy Vector System (T vector) was purchased from Promega (Madison, WI, USA).

The HaSNPV Bacmid HaBacHZ8 was constructed in our laboratory recently (H. Wang et al., unpublished data). The HaBacHZ8 was generated from the commercially existing BACTO-BAC ${ }^{\text {TM }}$ (Invitrogen, Carlsbad, CA, USA) of AcMNPV. An 8.5-kb fragment containing a low-copy-number mini $\mathrm{F}$ replicon, a selectable kanamycin resistance marker, and a lac $Z \alpha$ gene with attTn7 (the target site for bacterial transposon Tn7) was isolated by PCR out of the AcMNPV bacmid and inserted into the polyhedrin gene locus of HaSNPV genome (H. Wang et al., unpublished data).

\section{Preparation of Linear Fragment for Homologous Recombination}

To generate a linear fragment for re- placing the v-cathepsin ( $v$-cath) gene of the HaSNPV, a gene replacement vector $\mathrm{pVC} 33$ was first constructed. The upstream and downstream flanking sequences of the $v$-cath gene were obtained by PCR with the primers: A1: 5'CTCCGAGATCTGATTCGTTGTATAGTCGTGG-3', A2: 5'-AAGCTTGATATTTGAATGTACTTGCG- $3^{\prime}$, and B1: 5'-TCTAGATTCATGGGGAGAAGATTGG-3', B2: 5'-AGATCTTACCGAACTTTGTGCTATG- ${ }^{\prime}$, respectively. The restriction enzyme sites (in italics) were introduced to facilitate cloning. The two PCR products were first cloned into $\mathrm{T}$ vector and then into pBluescript $^{\circledR}$ SK (+) to create $\mathrm{pVC} 25$. Eventually, the $\mathrm{Cm}^{R}$ gene from pKD3 was cloned into the HindIII site of pVC25 to produce pVC33 (Figure 1).

The plasmid pVC33 was digested with $B g I I I$, and the linear fragment containing the upstream and downstream flanking sequence of the $v$-cath and the $\mathrm{Cm}^{R}$ gene were purified by gel electrophoresis.

\section{Preparation of Competent Cells Containing Bacmid Genome and Phage $\lambda$ Red System}

The HaBacHZ8 genome DNA was first electro-transformed into $\mathrm{BW}$ 25113 (pKD46), which contains phage $\lambda$ Red system in the plasmid pKD46 (Bio-Rad Laboratories, Hercules, CA, USA). Then, $200 \mu \mathrm{L}$ overnight culture of the resulting bacterial BW25113 (pKD46)/HaBacHZ8 were grown in 10-mL LB cultures in the presence of ampicilin and kanamycin at $30^{\circ} \mathrm{C}$. At $\mathrm{A}_{600}$ of 0.4-0.6, L-arabinose was added to the culture at a final concentration of $1 \mathrm{mM}$ for $1 \mathrm{~h}$ to induce phage $\lambda$ Red system expression. The competent cells were then concentrated 100fold and washed three times with icecold $10 \%$ glycerol. The competent cells were aliquoted into Eppendorf ${ }^{\circledR}$ tubes $(60 \mu \mathrm{L})$ on ice.

\section{Homologous Replacement}

Electroporation was done by adding 10-100 ng linearized DNA fragments into freshly made $60 \mu \mathrm{L}$ competent cells and subjecting them to $1.8 \mathrm{kV}$ according to the manufacturer's instructions using a MicroPulser ${ }^{\top \mathrm{M}}$ electro- transporation device (Bio-Rad Laboratories). These cells were transferred to $1 \mathrm{~mL}$ SOC medium without antibiotics and incubated for $1-2 \mathrm{~h}$ at $30^{\circ} \mathrm{C}$ with gentle shaking. The cells were collected by centrifugation at $10000 \times g$ for 20 $\mathrm{s}$, spread onto agar containing kanamycin and chloramphenicol, and incubated at $30^{\circ} \mathrm{C}$ for $48 \mathrm{~h}$. Positive colonies were inoculated into LB medium containing kanamycin and chloramphenicol. After reaching a saturated cell concentration, the recombinant bacmid DNAs were extracted according to the Invitrogen Bac-to-Bac baculovirus expression system manual. DY380 cells were used to maintain bacmid DNAs.

\section{Identification of the Recombinants}

PCR and endonuclease digestion were used to identify the recombinants. As the direction of the $\mathrm{Cm}^{R}$ gene cloned in $\mathrm{pVC} 33$ was opposite to that of the $v$-cath gene, the following two primers were designed for identifying the disruption of the $v$-cath gene: $\mathrm{C} 1$ : 5'-TTATACGCAAGACGACAAGG-3', which is an internal sequence of $\mathrm{Cm}^{\mathrm{R}}$ gene, and C2: 5'-GCGGCATTGGCAGGTTC-3' located at about $1.3 \mathrm{~kb}$ upstream of the translation start codon ATG of the $v$-cath gene (Figure 1). The DNA of recombinants was digested by BamHI, HindIII, BglII, and XhoI.

\section{RESULTS AND DISCUSSION}

A method for efficient generation of homologous recombinant baculoviral genomes by combing bacmid DNA and the phage $\lambda$ Red system is described in this paper. The disruption of the $v$-cath in HaBacmid HZ8 was used to demonstrate the validity of the approach. We obtained an average of $10^{3}-10^{4}$ positive colonies with $1 \mu \mathrm{g}$ linear fragments containing 1-kb homologous arms. Seven of the positive colonies were randomly picked up and analyzed by PCR and HindIII digestion. All showed correct replacement in the genome structure. One of the seven colonies was digested with BamHI, HindIII, BglII, and XhoI (Figure $2 \mathrm{~B}$ ). The restriction enzymes profile showed the expected fragment changes, indicating that the $\mathrm{v}$-cath 


\section{Short Technical Reports}

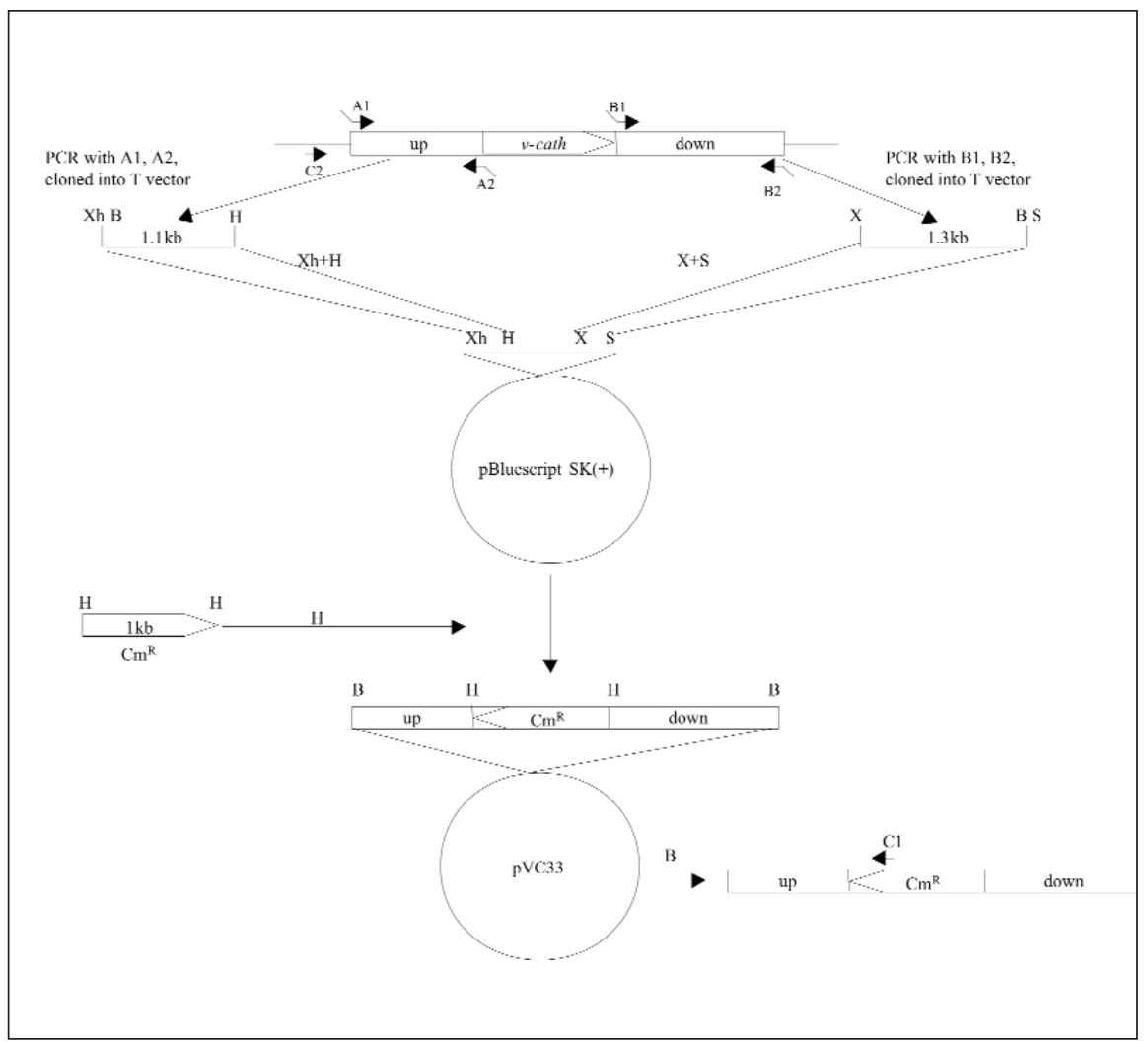

Figure 1. Procedure for generating linear homologous fragment for $v$-cath replacement. B, H, S, X, and Xh represent $B g I I I$, HindIII, SacI, XbaI and XhoI, respectively. The location of the primer sequences (A1, A2, B1, B2, C1, and C2) were indicated by arrows.

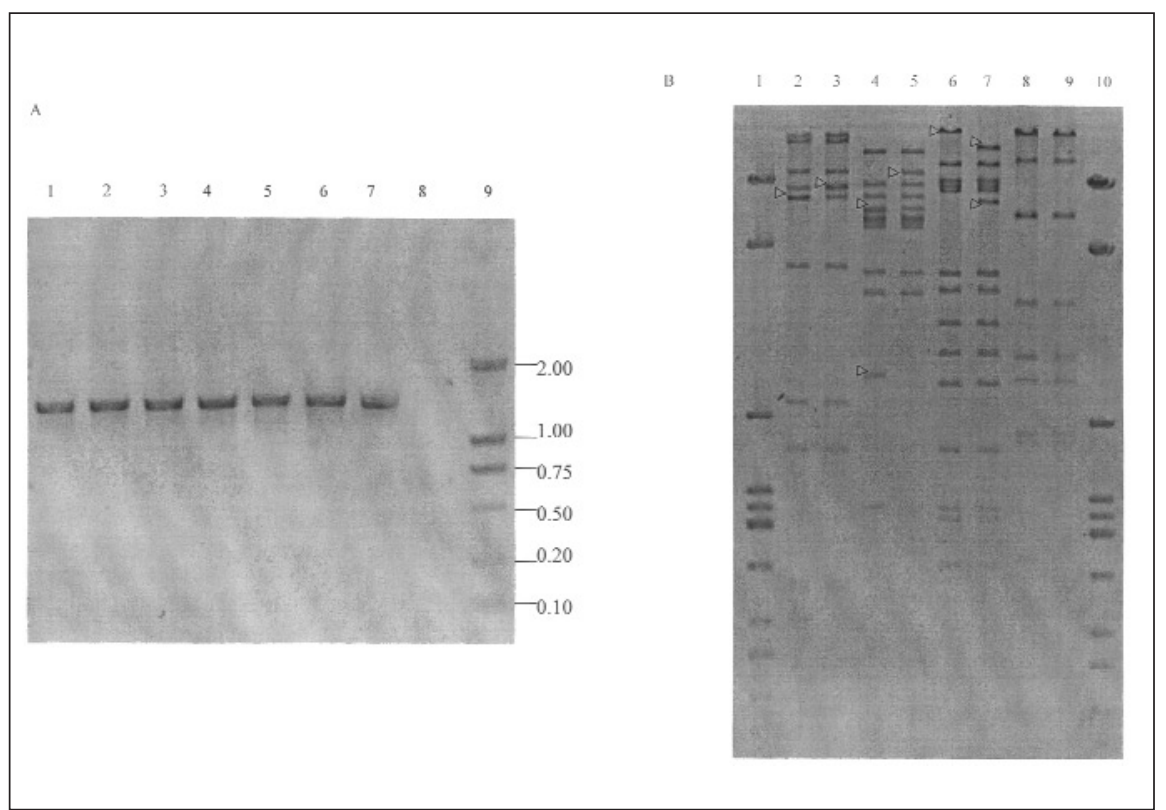

Figure 2. Identification of $\boldsymbol{v}$-cath-deleted recombinant genome. (A) PCR analysis with $\mathrm{C} 1$ and $\mathrm{C} 2$ as primers. The templates were: 1-7, Bacmid DNA from different colonies; 8, HaSNPV Bacmid $\mathrm{HaBacHZ8}$; and 9, molecular weight marker. (B) Comparison between the restriction enzyme profile of the recombinant DNA (lanes 2, 4, 6, and 8) and HaBacHZ8 DNA (lanes 3, 5, 7, and 9) digested with BamHI (lanes 2 and 3), HindIII (lanes 4 and 5), BglII (lanes 6 and 7), and XhoI (lanes 8 and 9), respectively. The arrows indicated the changes of the enzyme-digested fragments. Lanes 1 and 10, $\lambda$ DNA digested with BamHI-EcoRI-HindIII. 
gene of HaSNPV had been successfully replaced by the $C m^{R}$ gene.

The new method bypasses the timeconsuming procedures of the traditional co-transfection and plaque purification methods. The method is easy to use and reduces the required time from 4-6 weeks to several days because recombination is conducted in E. coli cells and selected with antibiotics. However, the method still needs a specific linear fragment for each target gene, and this step is as time consuming as the traditional method. Brune et al. (2) recently have developed a method of obtaining inactivated target herpesvirus genes by random insertioninterruption of Tn1721. We are now exploring the possibility of using a similar method in the bacmid system.

Although it is efficient to generate the recombinant baculoviral genomes with linear fragments containing about $1-\mathrm{kb}$ flanking sequence arms, it is possible to use shorter homologous arms. So far, the shortest flanking arms were about $100 \mathrm{bp}$. However, the transformation efficiency declined 10-100 times (data not shown).

Bideshi and Federici (1) described a procedure to disrupt AcMNPV genes in $E$. coli using the commercial Bac-toBac AcMNPV baculovirus. In their report, the homologous recombination of the baculovirus genome with a linear fragment occurred in a $r e c B C s b c B C E$. coli strain BJ8153, in which an alternative recombinant pathway was activated by the $s b c B C$ mutant. However, Yu et al. (14) have indicated that such mutant $r e c B C$ strains are extremely poor growing, defective for recombination, and do not support efficient replication of the many plasmids used in recombination work. In our laboratory, we found it difficult to obtain the recombinants using the $\operatorname{rec} B C \quad s b c B C$ system (data not shown). By contrast, in our hands, the current Red recombinant system has higher recombinant efficacy.

Although this method was illustrated only in constructing recombinant baculovirus, it can be easily extended to other large DNA viruses. As the recombination is made in $E$. coli, it is now available to obtain the deletion mutants of all viral genes, including baculoviral essential genes that cannot be deleted in insect cells.

\section{REFERENCES}

1.Bideshi, D.K. and B.A. Federici. 2000. The Trichoplusia $n i$ granulovirus helicase is unable to support replication of Autographa californica multicapsid nucleopolyhedrovirus in cells and larvae of T. ni. J. Gen. Virol. 81:1593-1599.

2.Brune, W., C. Ménard, U. Hobom, S. Odenbreit, M. Messerle, and U.H. Koszinowski. 1999. Rapid identification of essential and nonessential herpesvirus genes by direct transposon mutangenesis. Nat. Biotechnol. 17:360364.

3.Chen, X., W.F.J. Ijkel, R. Tarchini, X. Sun, H. Sandbrink, H. Wang, S. Peters, D. Zuidema et al. 2001. The sequence of the $\mathrm{He}$ licoverpa armigera single nucleocapsid nucleopolyhedrovirus genome. J. Gen. Virol. 82:241-257.

4.Datsenko, K.A. and B.L. Wanner. 2000. One-step inactivation of chromosomal genes in Escherichia coli K-12 using PCR products. Proc. Natl. Acad. Sci. USA 97:6640-6645.

5.Hayakawa, T., G.F. RohrMann, and Y. Hashimoto. 2000. Patterns of genome organization and content in lepidopteran baculovirus. Virology 278:1-12.

6.Jasin, M. and P. Schimmel. 1984. Deletion of an essential gene in Escherichia coli by sitespecific recombination with linear fragments. J. Bacteriol. 159:783-786.

7. Kuzminov, A. 1999. Recombinational repair of DNA damage in Escherichia coli and bacterialphage $\lambda$. Microb. Mol. Biol. Rev. 63:751813.

8.Link, A.J., D. Philips, and G.M. Church. 1997. Methods for generating precise deletions and insertions in the genome of wildtype Escherichia coli: application to open reading frame characterization. J. Bacteriol. 179:6228-6237.

9.Luckow, V.A., S.C. Lee, G.F. Barry, and P.O. Olins. 1993. Efficient generation of infectious recombinant baculoviruses by sitespecific transposon-mediated insertion of foreign genes into a baculovirus genome propagated in Escherichia coli. J. Virol. 67:4566-4579.

10.Murphy, K.C. 1998. Use of bacteriophage $\lambda$ recombination function to promote gene replacement in Escherichia coli. J. Bacteriol. 180:2063-2071.

11.O'Reily, D.R., L.K. Miller, and V.A. Luckow. 1992. Baculovirus Expression Vectors: A Laboratory Manual. W.H. Freeman and Company, New York.

12.Slater, S. and R. Maurer. 1993. Simple phagemid-based system for generating allele replacement in Escherichia coli. J. Bacteriol. 175:4260-4262.

13.Winans, S.C., S.J. Elledge, J.H. Krueger, and G.C. Walker. 1985. Site-directed insertion and deletion mutagenesis with cloned fragments in Escherichia coli. J. Bacteriol. 161:1219-1221.

14.Yu, D., H.M. Ellis, E.-C. Lee, N.A. Jenkins, N.G. Copeland, and L. Court. 2000. An efficient recombination system for chromosome engineering in Escherichia coli. Proc. Natl. Acad. Sci. USA 97:5978-5983.

15.Zhang, G.Y. 1989. Commercial viral insecti-
cide-Heliothis armigera viral insecticide in China. IPM Pract. 11:113.

16.Zhang, G. 1994. Research, development and application of Heliothis viral pesticide in China. Resources Environ. Yangtze Valley 3:1-6.

We thank Dr. Donald L. Court for providing DY380 strains and Dr. Barry L. Wanner for providing BW25113 (pKD46) and $p K D 3$. This research was supported partly by an $R \& D$ Special Project on Transgeneic Plants from the Ministry of Science and Technology of China (J00-A-003), the Hundred Talents Program, the Young Scientist Group projects, and kscx2-1-02 project from Chinese Academy of Sciences, and NSFC Projects (30025003, 39980001). Address correspondence to $\mathrm{Dr}$. Zhihong $\mathrm{Hu}$, Joint-Laboratory of Invertebrate Virology, Wuhan Institute of Virology, Chinese Academy of Sciences, Wuhan, Hubei, 430071, People's Republic of China.e-mail: huzh@ pentium.whiov.ac.cn

Received 22 August 2001; accepted 26 December 2001.

\section{S. Hou ${ }^{1,2}$, X. Chen ${ }^{2}$, H. Wang', M. Tao ${ }^{1}$, and $\mathrm{Z}$. Hu ${ }^{2}$ ${ }^{1}$ Huazhong Agricultural University \\ ${ }^{2}$ Wuhan Institute of Virology Chinese Academy of Sciences Wuhan, Hubei People's Republic of China}

\section{For reprints of this or any other article, contact Reprints@BioTechniques.com}

